\title{
Field and laboratory evaluation of fungicides for the control of Phytophthora fruit rot of papaya in far north Queensland, Australia
}

\author{
L.L. Vawdrey ${ }^{\text {a, }}{ }^{*}$, M. Male ${ }^{\text {b }}$, K.R.E. Grice ${ }^{\mathrm{c}}$ \\ ${ }^{a}$ Horticulture and Forestry Sciences, Department of Agriculture, Fisheries and Forestry, Centre for Wet Tropics Agriculture, South Johnstone, \\ Qld 4859, Australia \\ b PO Box 482, Helensvale, Qld 4212, Australia \\ ${ }^{\mathrm{c}}$ Horticulture and Forestry Sciences, Department of Agriculture, Fisheries and Forestry, Centre for Tropical Agriculture, Mareeba, Qld 4880, Australia
}

\section{A R T I C L E I N F O}

\section{Article history:}

Received 17 April 2014

Received in revised form

10 October 2014

Accepted 12 October 2014

Available online 30 October 2014

\section{Keywords:}

Carica papaya

Papaw

Paw paw

Fungicides

Tropical fruit

\begin{abstract}
A B S T R A C T
Results from the first of two artificially inoculated field experiments showed foliar applications of copper hydroxide (Blue Shield Copper) at $600 \mathrm{~g}$ a.i. $/ 100 \mathrm{~L}^{-1}$ (0\% infected fruit), copper hydroxide + metalaxyl-M (Ridomil Gold Plus.) at $877.5 \mathrm{~g}$ a.i./100 L ${ }^{-1}(0.27 \%)$, metiram + pyraclostrobin (Aero) at $720 \mathrm{~g}$ a.i./100 L ${ }^{-1}$ (0.51\%), chlorothalonil (Bravo WeatherStik) at $994 \mathrm{~g}$ a.i./ $100 \mathrm{~L}^{-1}(0.63 \%)$ and cuprous oxide (Nordox 750 WG) at $990 \mathrm{~g}$ a.i./ $100 \mathrm{~L}^{-1}(0.8 \%)$ of water significantly reduced the percentage of infected fruit compared to potassium phosphonate (Agri-Fos 600 ) at $1200 \mathrm{~g}$ a.i./100 $\mathrm{L}^{-1}(8.22 \%)$, dimethomorph (Acrobat) at $108 \mathrm{~g}$ a.i./100 $\mathrm{L}^{-1}(11.18 \%)$ and the untreated control (16\%). Results from the second experiment showed fruit sprayed with copper hydroxide (Champ Dry Prill) at 300 (2.0\% infected fruit), 375 (0.4\%) and $450 \mathrm{~g}$ a.i./ $100 \mathrm{~L}^{-1}(0.6 \%)$ and metiram + pyraclostrobin (Aero) at $360(2.8 \%), 480(0.6 \%)$ and $600 \mathrm{~g}$ a.i. $/ 100 \mathrm{~L}^{-1}$ of water $(1.0 \%)$ significantly reduced the percentage of infected fruit compared to the untreated control (19.4\%). Foliar sprays of copper hydroxide at $375 \mathrm{~g}$ a.i./ $100 \mathrm{~L}^{-1}$ in rotation with chlorothalonil at $994 \mathrm{~g}$ a.i./ $100 \mathrm{~L}^{-1}$ every two weeks is now recommended to growers for controlling Phytophthora fruit rot of papaya.
\end{abstract}

Crown Copyright $\odot 2014$ Published by Elsevier Ltd. All rights reserved.

\section{Introduction}

The northern Queensland papaya industry (latitudes $18.16^{\circ} \mathrm{S}$ to $17.00^{\circ} \mathrm{S}$ ) comprises approximately $90 \%$ of all papaya (Carica papaya) grown in Australia (Diczbalis et al. 2012). Phytophthora-related diseases (e.g. root rot, stem rot and fruit rot) caused by $P$. palmivora are a significant constraint to the profitability and further expansion of the Australian papaya industry which has an estimated value of \$18-25 Million (Diczbalis et al. 2012). These diseases are particularly damaging for growers on the wet tropical coast of far north Queensland (Diczbalis et al. 2012) where the average annual rainfall is in excess of $3000 \mathrm{~mm}$ with a distinct wet season from January to April. Following periods of heavy rainfall, entire columns of fruit can be lost to Phytophthora fruit rot. Mature fruit infected with $P$. palmivora become covered with off-white mycelium that produces masses of sporangia which contain highly infective zoospores (Hunter and Buddenhagen, 1969). These spores are a source of inoculum dispersed by wind-blown rain (Hunter and Kunimoto,

\footnotetext{
* Corresponding author.

E-mail address: lynton.vawdrey@daff.qld.gov.au (L.L. Vawdrey).
}

1973). Observations by Hamill (1987) suggested that sporangia produced in the soil can spread to the aerial parts of the plant by wind-blown rain. Once on the ground, infected fruit are also important reservoirs of inoculum for root and fruit infections (Ko, 1982).

Control of Phytophthora fruit rot is dependent on an integrated system of both cultural and chemical control measures. This involves growing papaya on well-drained soils, the removal of infected fruit from the field, the establishment of grassed areas between the rows of papaya to reduce inoculum splash to aerial parts of the plant, and regular foliar spray applications with copper hydroxide (Chay-Prove, 2000). Copper hydroxide has been used at the rate of 100-150 $\mathrm{g}$ a.i./100 L but according to growers the results obtained with this chemical at that rate of application are always disappointing (J. Zappala, personal communication). There are presently no other chemicals registered for the control of Phytophthora fruit rot of papaya. Although all papaya cultivars are affected by this disease, it is the much sought after red-fleshed Solo types which are most susceptible (Chay-Prove, 2000).

This paper reports on two field experiments conducted from 2009 to 2012 which evaluated a range of chemicals with known efficacy against Phytophthora spp. (Alvarez and Nelson, 1982; 
Mathereon and Porchas, 2000; Rebollar-Alviter et al., 2007; Washington and McGee, 2000). The chemicals included copper hydroxide, copper sulphate, cuprous oxide, copper hydroxide + metalaxyl-M, metiram + pyraclostrobin, chlorothalonil, potassium phosphonate and dimethomorph; and were evaluated during the 'wet season' when disease pressure due to $P$. palmivora would normally be high. All these chemicals were used at rates of application well above what is normally recommended in other crops to control Phytophthora-related diseases as it was thought that higher rates would be needed to control the severe disease pressure situations which often occur following prolonged wet weather. It was also felt that the use of curative fungicides such as copper hydroxide + metalaxyl-M, metiram + pyraclostrobin and dimethmorph would be of benefit to growers during these periods of high disease pressure. Laboratory experiments further assessed the efficacy of these chemicals against Phytophthora fruit rot.

\section{Materials and methods}

\subsection{Site description and experimental design}

Two field experiments were conducted on red-brown light clay (Innisfail Series) soil at the Queensland Department of Agriculture, Fisheries and Forestry, South Johnstone Research Station near Innisfail. Each trial-site had been under weed fallow for many years. The experimental sites were deep-ripped and rotary-hoed and single row mounds ( $0.60 \mathrm{~m}$ high) formed. Both trials received an application of basal fertiliser $(12.7 \% \mathrm{~N}, 14.2 \% \mathrm{P}, 10.9 \% \mathrm{~K}, 2.4 \% \mathrm{~S}$, and $2 \% \mathrm{Zn}$ ) at the rate of $266 \mathrm{~kg} / \mathrm{ha}$, a side dressing of $19.3 \% \mathrm{~N}, 0 \% \mathrm{P}$ and $28.4 \% \mathrm{~K}$ at the rate of $336 \mathrm{~kg} / \mathrm{ha}$ and two applications of urea $(39 \mathrm{~kg} /$ ha) throughout the growing season. The urea was applied via a mini-sprinkler irrigation system. Papaya seedlings of the red papaya cv. Sunrise Solo which is highly susceptible to Phytophthora fruit rot were grown in pasteurized potting mix for 10 weeks before transplanting. As this cultivar is gynodioecious, four seedlings were transplanted at each plant position and these were thinned to a single hermaphrodite plant per position at flowering (approximately 16 weeks after transplanting) when the sex could be determined.

The site of the first experiment was transplanted on the 11 June 2009 and was divided into 32 plots (each $15 \mathrm{~m} \times 4 \mathrm{~m}$ ) consisting of 8 treatments and 4 replications arranged as a randomised complete block. Plots consisted of a single row of 10 plants $1.5 \mathrm{~m}$ apart with a single row of unsprayed plants separating treatments. Trees had a column of fruit at the commencement of the experiment.

The site of the second experiment was transplanted on the 9 June 2011 and was divided into 35 plots (each $10.5 \mathrm{~m} \times 4 \mathrm{~m}$ ) consisting of 7 treatments and 5 replications arranged as a randomised complete block. Plots consisted of a single row of 7 treated plants with a single row of unsprayed plants separating treatments. Trees had a column of fruit at the commencement of the experiment.

\subsection{Inoculum preparation and plant inoculation}

Due to the likelihood of little or no natural infection, both experimental sites were artificially inoculated with $P$. palmivora. An isolate of $P$. palmivora was acquired from a diseased papaya fruit by excising small sections of rotted fruit and plating onto $\mathrm{P}_{10} \mathrm{ARP}+\mathrm{H}$ culture media. Inoculum was produced from a single sporangium isolate (BRIP 61509) obtained from a sporulating sector of the $\mathrm{P}_{10}$ $\mathrm{ARP}+\mathrm{H}$ colony. Inoculum used in experiments consisted of 3-4 week-old axenic cultures of the single sporangium isolate grown on potato carrot agar (potato/carrot infusion consisting of potato, $20 \mathrm{~g}$; carrot, 20 g; Bacto agar, 15 g; distilled water, $1000 \mathrm{~mL}$ ) under near
UV light at $27^{\circ} \mathrm{C}$. The agar cultures (heavy with sporangia) were macerated in a small amount of distilled water in a Waring Blender for $45 \mathrm{~s}$ before being further diluted in distilled water to give a total volume of $150 \mathrm{~mL}$ of water per culture plate. Sufficient of the spore/ mycelia suspension was prepared and approximately $100 \mathrm{~mL}$ of the suspension was sprayed with a Solo garden sprayer onto both sides of the fruit column of a single tree in the guard row directly opposite the centre of each treated plot. The sprayed fruit column was then covered with a polythene sheet which was tied off at the top, stapled down the side and tied-off at the bottom with flagging tape (Fig. 1). The polythene sheet remained in place for 4 days to retain a high humidity and so encourage the development of the disease. Fruit columns were inoculated on the 12 March 2010 (experiment 1) and the 22 February 2012 (experiment 2) when rain was forecast for the local area. As the disease developed within the fruit column (Fig. 1), affected fruit were moved to adjacent fruit columns within the guard rows to help spread the disease uniformly throughout the trial-site. Rainfall data was also collected from the nearby South Johnstone weather station.

\subsection{Treatment application}

\subsubsection{Experiment 1}

The chemical treatments included Blue Shield Copper DF (active ingredients: 50\% copper hydroxide, Bayer) applied at $600 \mathrm{~g}$ ai/ $100 \mathrm{~L}^{-1}$, Ridomil Gold Plus WG (a.i.: $81 \%$ copper hydroxide, $6.75 \%$ metalaxyl-M, Syngenta) applied at $877.5 \mathrm{~g}$ a.i./100 L $\mathrm{L}^{-1}$, Aero WG (a.i.: 55\% metiram, 5\% pyraclostrobin, Nufarm) applied at $720 \mathrm{~g}$ a.i./ $100 \mathrm{~L}^{-1}$, Bravo WeatherStik SC (a.i. $720 \mathrm{~g} / \mathrm{L}$ chlorothalonil, Syngenta) applied at $994 \mathrm{~g}$ a.i./100 L, Red Copper WG (a.i. 75\% cuprous oxide, Nordox Australia) applied $990 \mathrm{~g}$ a.i./100 L ${ }^{-1}$, Agri-Fos Supa $600 \mathrm{~L}$ (a.i. 60\% potassium phosphonate, Agrichem) applied at $1200 \mathrm{~g}$ a.i./ $100 \mathrm{~L}^{-1}$ and Acrobat SC (a.i. 50\% dimethomorph, BASF) applied at $108 \mathrm{~g}$ a.i./100 $\mathrm{L}^{-1}$ of water. Eight applications of these treatments were made to the appropriate plots every two weeks commencing on the 5 January 2010. Approximately 167 L/ha of water were used to spray the fruit columns. The wetting agent Agral was applied at the rate of $0.04 \%$ with all chemical treatments except chlorothalonil as this mixture is known to be phytotoxic (CDMS, 2014). All chemical treatments were applied with a motorized backpack mist blower (Solo). An untreated control plot was included for comparison.

\subsubsection{Experiment 2}

The chemical treatments used were the two most effective chemicals from experiment 1, Champ Dry Prill-WG (a.i. 37.5\% copper hydroxide, Nufarm) applied at 300, 375 and $450 \mathrm{~g}$ a.i./100 $\mathrm{L}^{-1}$ and Aero WG (a.i. 55\% metiram, 5\% pyraclostrobin, Nufarm) applied at 360,480 and $600 \mathrm{~g}$ a.i./ $100 \mathrm{~L}^{-1}$ of water. Seven applications of these treatments were made to the appropriate plots every two weeks commencing on the 23 January 2012. Approximately $238 \mathrm{~L} /$ $\mathrm{ha}^{-1}$ of water was used to spray the fruit columns and foliage. The wetting agent Agral was applied at the rate of $0.04 \%$ with all chemical treatments. All chemical treatments were applied with a motorized backpack mist blower (Solo). An untreated control plot was included for comparison.

\subsection{Disease assessments}

In experiment 1 , fruit was harvested weekly for 12 weeks commencing on the 8 February 2010. The total number of Phytophthora affected fruit and the total number of fruit harvested during this period was recorded and the cumulative total percentage disease affected fruit calculated. All fruit with a diameter greater than $7.0 \mathrm{~cm}$ were harvested. Following the establishment of 

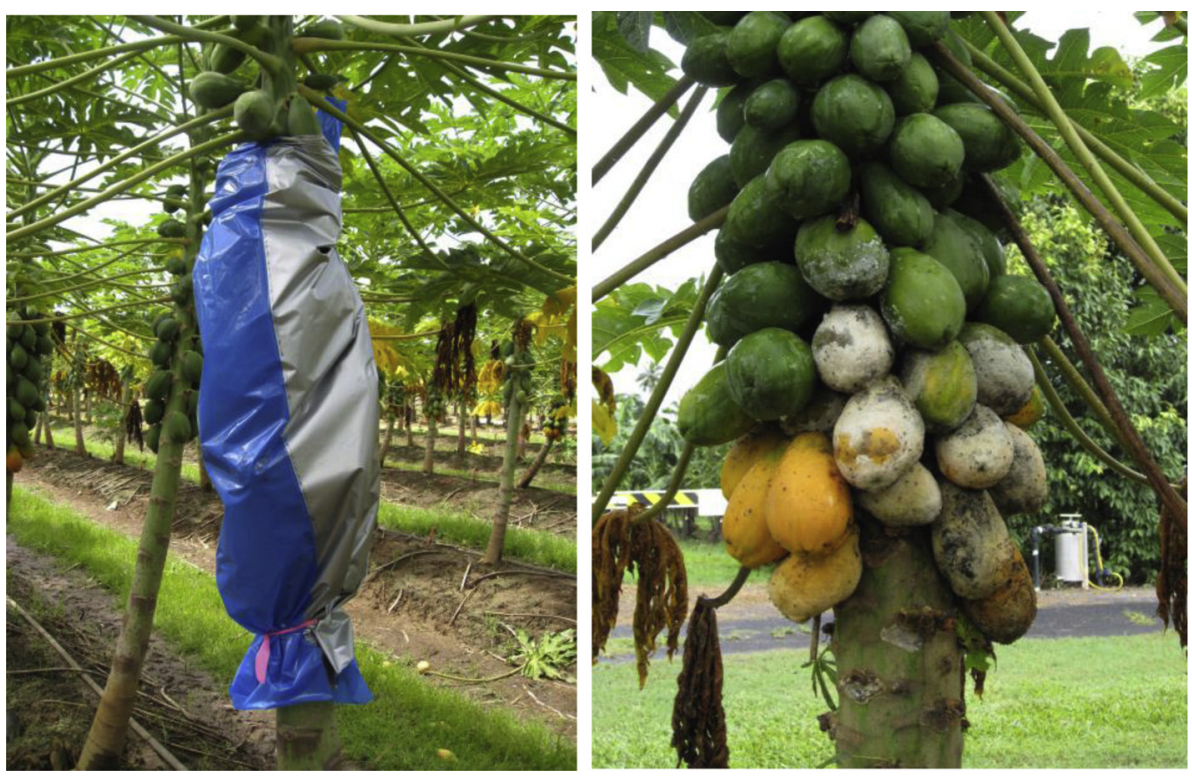

Fig. 1. Artificial inoculation of papaya fruit columns with Phytophthora palmivora.

the disease in the guard rows, disease severity assessments were conducted on the 12 April and the 27 April 2010. Three fruit columns were assessed per plot using the following disease severity scale; 1 , no disease, $2,1-10 \%$ of fruit column affected, $3,11-20 \%$ of fruit column affected, $4,21-30 \%$ of fruit column affected, $5,31-50 \%$ of fruit column affected, $6,>51 \%$ of fruit column affected. In experiment 2, fruit was harvested weekly for 7 weeks (number of fruit with and without disease) commencing on the 6 March 2012 and the cumulative total number of marketable fruit was recorded and the cumulative total percentage of Phytophthora infected fruit calculated. Fruit were considered marketable if they had a diameter greater than $7.0 \mathrm{~cm}$ and were free of major blemishes including Phytophthora rot.

\subsection{In vitro studies}

In 2010, an in vitro fruit bioassay was used to further assess the efficacy of the seven chemical treatments used in the 2010 field experiment. Two mature fruit (at colour break stage) were each sprayed with the appropriate chemical treatment and allowed to dry before being sprayed with 200 sporangia/mL of $P$. palmivora (BRIP isolate 61509) and placed in a hardened plastic container. The inoculum used in this study was prepared as previously mentioned. Three replicate plastic containers per treatment were placed in an incubator in the dark at $27^{\circ} \mathrm{C}$ for 3 days in a completely randomised design. An inoculated untreated control was included for comparison. Fruit were checked every $24 \mathrm{~h}$ for fungal growth and were assessed 4 days after inoculation for fruit rot. The following scaled index of disease symptom severity was used where 1 , no disease; 2 , $1-10 \%$ of fruit area affected; $3,11-20 \%$ of fruit area affected; 4 , $21-30 \%$ of fruit area affected; $5,31-50 \%$ of fruit area affected; and $6,>51 \%$ of fruit area affected. The experiment was repeated once.

In 2012, a similar laboratory experiment compared four rates of application of copper hydroxide with two rates of copper sulphate and an inoculated untreated control. Two mature fruit (at colour break stage) were each sprayed with the appropriate chemical treatment and allowed to dry before being sprayed with 200 sporangia/mL of $P$. palmivora (BRIP isolate 61509) and placed in a hardened plastic container. The inoculum used in in this study was prepared as previously mentioned. Three replicate plastic containers per treatment were placed in an incubator in the dark at $27{ }^{\circ} \mathrm{C}$ for 6 days in a completely randomised design. Fruit were checked daily for fungal growth and assessed on days 4, 5 and 6 using the scaled index of disease symptom severity mentioned previously. The experiment was repeated once.

\subsection{Data analysis}

Statistical analyses were conducted using Genstat 5 release 4.1 data analysis software (Lawes agricultural Trust, Rothamsted Experimental Station). A one-way ANOVA was used to analyse the disease severity assessments, cumulative totals of percentage disease affected fruit and number of disease affected fruit. Where a treatment effect was found to be significant, pair-wise testing was performed between treatment means using the protected least significance difference test.

\section{Results}

\subsection{Field experiments}

\subsubsection{Experiment 1}

Symptoms of Phytophthora fruit rot were apparent at the removal of the polythene sheets 4 days after inoculation (Fig. 1) and the disease continued to develop slowly throughout the trial-site following periods of heavy rainfall. As the trial progressed, some of the inoculated guard row trees developed Phytophthora stem rot and died. Results from the assessments of disease damage to the fruit column conducted on the 12 April showed copper hydroxide, copper hydroxide + metalaxyl-M, metiram + pyraclostrobin, chlorothalonil and cuprous oxide significantly $(P<0.05)$ reduced the severity of damage to the fruit column compared to potassium phosphonate, dimethomorph and the untreated control (Table 1). The assessment conducted on the 27 April showed copper hydroxide, copper hydroxide + metalaxyl-M, metiram + pyraclostrobin, chlorothalonil and cuprous oxide significantly $(P<0.05)$ reduced the severity of disease on the fruit column compared to dimethomorph and the untreated control. The disease severity in dimethomorph treated plots was not significantly different $(P<0.05)$ to the untreated control. Potassium phosphonate significantly $(P<0.05)$ reduced the 
Table 1

Disease severity and cumulative totals of the percentage incidence of Phytophthora fruit rot of papaya following the spray application of various fungicides in a field experiment established in June 2009.

\begin{tabular}{lllll}
\hline Treatment & $\begin{array}{l}\text { Application } \\
\text { rate } \\
\left(\mathrm{g} \text { a.i. } / 100 \mathrm{~L}^{-1}\right)\end{array}$ & $\begin{array}{l}\text { Disease } \\
\text { severity }^{\mathrm{a}, \mathrm{b}} \\
\left(12 \text { April }^{2}\right)\end{array}$ & $\begin{array}{l}\text { Disease } \\
\text { severity } \\
(27 \mathrm{a}, \mathrm{b} r i l)\end{array}$ & $\begin{array}{l}\text { \% infected } \\
\text { fruit }^{\mathrm{b}}\end{array}$ \\
\hline 1. Untreated & - & $1.50 \mathrm{~b}$ & $1.75 \mathrm{c}$ & $16.55 \mathrm{c}$ \\
2. Copper hydroxide & 600 & $1.00 \mathrm{a}$ & $1.00 \mathrm{a}$ & $0.00 \mathrm{a}$ \\
3. Copper hydroxide & $810+67.5$ & $1.05 \mathrm{a}$ & $1.00 \mathrm{a}$ & $0.27 \mathrm{a}$ \\
$\quad+$ metalaxyl-M & & & & \\
4. Metiram + pyraclostrobin & $660+60$ & $1.05 \mathrm{a}$ & $1.05 \mathrm{a}$ & $0.51 \mathrm{a}$ \\
5. Chlorothalonil & 994 & $1.00 \mathrm{a}$ & $1.00 \mathrm{a}$ & $0.63 \mathrm{a}$ \\
6. Cuprous oxide & 990 & $1.10 \mathrm{a}$ & $1.00 \mathrm{a}$ & $0.80 \mathrm{a}$ \\
7. Potassium phosphonate & 1200 & $1.45 \mathrm{~b}$ & $1.30 \mathrm{ab}$ & $8.22 \mathrm{~b}$ \\
8. Dimethomorph & 108 & $1.50 \mathrm{~b}$ & $1.55 \mathrm{bc}$ & $11.18 \mathrm{bc}$ \\
LSD $(P=0.05)$ & - & 0.311 & 0.447 & 6.920 \\
\hline
\end{tabular}

a Treatment means are a scaled index of disease severity where 1 , no disease, 2 , $1-10 \%$ of fruit column affected, $3,11-20 \%$ of fruit column affected, $4,21-30 \%$ of fruit column affected, $5,31-50 \%$ of fruit column affected, $6,>51 \%$ of fruit column affected.

${ }^{\mathrm{b}}$ Means followed by the same letter are not significantly different $(P=0.05)$.

severity of Phytophthora fruit rot compared to the untreated control. The cumulative total percentage of disease affected fruit calculated from the weekly fruit harvests showed copper hydroxide $(0 \%$ diseased fruit), copper hydroxide + metalaxyl-M (0.27\%), metiram + pyraclostrobin (0.51\%), chlorothalonil $(0.63 \%)$ and cuprous oxide $(0.80 \%)$ effectively controlled the disease $(P<0.05)$ compared to dimethomorph (11.18\%), potassium phosphonate $(8.22 \%)$ and the untreated control (16.55\%). The disease severity ratings and the cumulative totals of the percentage disease affected fruit showed similar treatment differences.

\subsubsection{Experiment 2}

Weekly fruit harvests were conducted from the 20 February to the 11 April 2012. A heavy prolonged wet season favourable for disease development failed to develop over the summer, however disease did develop following the artificial inoculation of the site with P. palmivora. Results from the cumulative total percentage of disease affected fruit harvested (Table 2) showed that all chemical treatments (0.4-2.8\% diseased fruit) significantly reduced the incidence of Phytophthora fruit rot compared to the untreated control (19.4\%) and produced more marketable fruit than the untreated control. Copper hydroxide at $375 \mathrm{~g}$ a.i./100 $\mathrm{L}^{-1}$ had the lowest incidence of fruit rot but was not significantly different from the other chemical treatments (see Table 2).

\subsection{In vitro studies}

In the in vitro experiment conducted in 2010, off-white mycelial growth was evident on fruit in the untreated control treatment 3

Table 2

Cumulative totals of the number of marketable fruit and percentage incidence of Phytophthora fruit rot of papaya following spray applications with copper hydroxide and pyraclostrobin + thiram in a field experiment established in June 2011.

\begin{tabular}{lllc}
\hline Treatment & $\begin{array}{l}\text { Application rate } \\
(\mathrm{g} \text { a.i./100 L }\end{array}$ & $\begin{array}{l}\text { No. of } \\
\text { marketable } \\
\text { fruit }^{\mathrm{a}}\end{array}$ & $\begin{array}{l}\text { \% infected } \\
\text { fruit }^{\mathrm{a}}\end{array}$ \\
\hline 1. Untreated control - & - & $34.8 \mathrm{~b}$ & $19.4 \mathrm{~b}$ \\
2. Copper hydroxide & 300 & $61.4 \mathrm{a}$ & $2.0 \mathrm{a}$ \\
3. Copper hydroxide & 375 & $62.4 \mathrm{a}$ & $0.4 \mathrm{a}$ \\
4. Copper hydroxide & 450 & $63.8 \mathrm{a}$ & $0.6 \mathrm{a}$ \\
5. Metiram + pyraclostrobin & $330+30$ & $53.6 \mathrm{a}$ & $2.8 \mathrm{a}$ \\
6. Metiram + pyraclostrobin & $440+40$ & $54.2 \mathrm{a}$ & $0.6 \mathrm{a}$ \\
7. Metiram + pyraclostrobin & $550+50$ & $66.4 \mathrm{a}$ & $1.0 \mathrm{a}$ \\
LSD $(P=0.05)$ & - & 16.26 & 6.08 \\
\hline
\end{tabular}

a Means followed by the same letter are nor significantly different $(P=0.05)$.
Table 3

In vitro study of various fungicides on Phytophthora fruit rot severity, 4 days after inoculation with sporangia of $P$. palmivora.

\begin{tabular}{lll}
\hline Treatment & $\begin{array}{l}\text { Application rate } \\
\left(\mathrm{g} \text { a.i. } / 100 \mathrm{~L}^{-1}\right)\end{array}$ & $\begin{array}{l}\text { Disease } \\
\text { severity }^{\mathrm{a}, \mathrm{b}}(1-6)\end{array}$ \\
\hline $\begin{array}{l}\text { 1. Untreated control } \\
\text { 2. Copper hydroxide }\end{array}$ & - & $4.67 \mathrm{~b}$ \\
3. Copper hydroxide & 600 & $1.17 \mathrm{a}$ \\
$\quad+$ metalaxyl-M & $810+67.5$ & $1.00 \mathrm{a}$ \\
4. Metiram + pyraclostrobin & $660+60$ & $1.00 \mathrm{a}$ \\
5. Chlorothalonil & 994 & $4.33 \mathrm{~b}$ \\
6. Cuprous oxide & 990 & $1.00 \mathrm{a}$ \\
7. Potassium phosphonate & 1200 & $3.33 \mathrm{~b}$ \\
8. Dimethomorph & 108 & $1.00 \mathrm{a}$ \\
LSD $(P=0.05)$ & - & 1.6 \\
\hline
\end{tabular}

a Fruit were assessed on a scaled index of disease symptom severity where 1 , no disease; $2,1-10 \%$ of fruit area affected; $3,11-20 \%$ of fruit area affected; $4,21-30 \%$ of fruit area affected; $5,31-50 \%$ of fruit area affected; and $6,>51 \%$ of fruit area affected).

b Means followed by the same letter are not significantly different $(P=0.05)$.

days after inoculation. P. palmivora was re-isolated from these disease affected fruit. The disease assessment conducted 4 days after inoculation (Table 3) showed there was no significant $(P<0.05)$ difference in Phytophthora fruit rot severity between copper hydroxide at $600 \mathrm{~g}$ a.i./100 $\mathrm{L}^{-1}$, copper hydroxide + metalaxyl-M at $810+67.5 \mathrm{~g}$ a.i. $/ 100 \mathrm{~L}^{-1}$, metiram + pyraclostrobin at $660+60 \mathrm{~g}$ a.i. $/ 100 \mathrm{~L}^{-1}$, cuprous oxide at $990 \mathrm{~g}$ a.i./100 $\mathrm{L}^{-1}$ and dimethomorph at $108 \mathrm{~g}$ a.i./100 $\mathrm{L}^{-1}$. Chlorothalonil at $994 \mathrm{~g}$ a.i. $/ 100 \mathrm{~L}^{-1}$ and potassium phosphonate at $1200 \mathrm{~g}$ a.i./ $100 \mathrm{~L}^{-1}$ were significantly $(P<0.05)$ less effective than the other chemical treatments.

In the second in vitro experiment conducted in 2012, (Table 4) off-white mycelial growth reminiscent of Phytophthora was evident 3 days after inoculation. As with the previous experiment, P. palmivora was re-isolated from disease affected fruit. Results from the experiment showed that 4 days after inoculation, fruit treated with copper hydroxide at 225, 300 and $375 \mathrm{~g}$ a.i./100 $\mathrm{L}^{-1}$ had significantly $(P<0.05)$ less fruit rot than the untreated control. Copper hydroxide at $375 \mathrm{~g}$ a.i./ $100 \mathrm{~L}^{-1}$ and copper sulphate at $380 \mathrm{~g}$ a.i./100 $\mathrm{L}^{-1}$ proved more effective $(P<0.05)$ than copper hydroxide at $150 \mathrm{~g}$ a.i./ $100 \mathrm{~L}^{-1}$ and copper sulphate at $152 \mathrm{~g}$ a.i./ $100 \mathrm{~L}^{-1}$. The assessments done 5 and 6 days after inoculation showed copper hydroxide at 225,300 and $375 \mathrm{~g}$ a.i./ $100 \mathrm{~L}^{-1}$ and copper sulphate at $380 \mathrm{~g}$ a.i./100 $\mathrm{L}^{-1}$ effectively controlled the disease $(P<0.05)$

Table 4

In vitro study of various rates of application of copper hydroxide and copper sulphate on Phytophthora fruit rot severity, 4, 5 and 6 days after inoculation with sporangia of P. palmivora.

\begin{tabular}{lllll}
\hline Treatment & $\begin{array}{l}\text { Application rate } \\
\left(\mathrm{g} \text { a.i. } / 100 \mathrm{~L}^{-1}\right)\end{array}$ & \multicolumn{3}{l}{ Disease severity on ${ }^{\mathrm{a}, \mathrm{b}}$} \\
\cline { 3 - 5 } & & Day 4 & Day 5 & Day 6 \\
\hline 1. Copper hydroxide & 375 & $1.00 \mathrm{a}$ & $1.16 \mathrm{a}$ & $1.66 \mathrm{a}$ \\
2. Copper hydroxide & 300 & $1.66 \mathrm{ab}$ & $1.66 \mathrm{a}$ & $2.33 \mathrm{a}$ \\
3. Copper hydroxide & 225 & $1.66 \mathrm{ab}$ & $1.83 \mathrm{a}$ & $1.83 \mathrm{a}$ \\
4 Copper hydroxide & 150 & $2.83 \mathrm{~b}$ & $3.16 \mathrm{~b}$ & $4.33 \mathrm{~b}$ \\
5. Copper sulphate & 380 & $1.33 \mathrm{a}$ & $1.83 \mathrm{a}$ & $2.33 \mathrm{a}$ \\
6. Copper sulphate & 152 & $2.66 \mathrm{~b}$ & $3.33 \mathrm{~b}$ & $4.16 \mathrm{~b}$ \\
7. Untreated & - & $5.00 \mathrm{c}$ & $5.66 \mathrm{c}$ & $6.00 \mathrm{c}$ \\
LSD $(P=0.05)$ & - & 1.25 & 1.31 & 1.68 \\
\hline
\end{tabular}

${ }^{\text {a }}$ Fruit were assessed on a scaled index of disease symptom severity where 1 , no disease; $2,1-10 \%$ of fruit area affected; $3,11-20 \%$ of fruit area affected; $4,21-30 \%$ of fruit area affected; $5,31-50 \%$ of fruit area affected; and $6,>51 \%$ of fruit area affected).

b Means followed by the same letter are not significantly different $(P=0.05)$. 
compared to copper hydroxide at $150 \mathrm{~g}$ a.i. $/ 100 \mathrm{~L}^{-1}$, copper sulphate at $152 \mathrm{~g}$ a.i./ $100 \mathrm{~L}^{-1}$ and the untreated control.

\section{Discussion}

Phytophthora fruit rot proved to be a damaging disease following periods of high rainfall causing a significant reduction in marketable fruit (16-19\% of fruit in untreated plots). Although the incidence of disease was not as severe as in some seasons, the artificial inoculation of both field experiments with $P$. palmivora proved a suitable method of establishing a disease epidemic in the field which enabled the reliable identification of effective chemicals. Hunter and Kunimoto (1973) reported that the germination and growth of sporangia is dependent on many hours of $100 \%$ relative humidity. The artificial inoculation methods used in our field experiment and in vitro studies enabled us to reproduce conditions of high relative humidity which was favourable for disease development.

Pyraclostrobin plus metiram and metalaxyl-M plus copper hydroxide are formulated fungicide mixtures with both systemic and protectant properties (Worthing and Hance, 1991). In our experiments, these fungicides proved very effective at controlling Phytophthora fruit rot in both the laboratory and field studies. Unfortunately, the continuous use of these fungicides is known to lead to the development of fungicide resistance strains (Lucas et al. (1990) and as chemical applications are required every two weeks during the 'wet season,' the risk of fungicide resistance is very high. CropLife Australia (2013) recommends that growers rotate applications of the 'at risk' systemic fungicide with fungicides from a different chemical group and limit the number of systemic fungicide applications per season as a means of managing fungicide resistance.

Chlorothalonil is a broad spectrum protectant fungicide and our research showed it was more effective against $P$. palmivora in the field than in the in vitro study. Similar research by Alvarez and Nelson (1982) also found that weekly field sprays with chlorothalonil resulted in 25-34\% fewer Phytophthora affected papaya trees. However research by Alvarez et al. (1977) showed papaya fruit which were sprayed in the field with chlorothalonil and then harvested and inoculated with zoospores of $P$. palmivora had only slight protection against Phytophthora fruit rot. They concluded that the inoculum level and the incubation time used in the detached fruit bioassay exceeded that which would occur naturally in the field. As chlorothalonil at $994 \mathrm{~g}$ a.i./ha effectively controlled Phytophthora fruit rot in our field experiment it would also be a suitable candidate in an alternating spray program with copper hydroxide. Chlorothalonil is currently permitted for use by the Australian papaya industry for the control of the leaf diseases, brown spot and black spot, at the rate of 1296-1656 g a.i./ $/ \mathrm{ha}^{-1}$.

In previous research, Vawdrey and Westerhuis (2007) showed that foliar sprays with potassium phosphonate every two weeks significantly reduced the incidence of Phytophthora root rot in papaya by $47 \%$. However our use of potassium phosphonate to control Phytophthora fruit rot showed it provided a level of control but was not as effective as the majority of other chemicals tested. The poor result achieved with dimethomorph was also most surprising as Mathereon and Porchas (2000) had reported that dimethomorph was a systemic fungicide which was most effective at reducing mycelial growth, sporangium formation and the germination of encysted zoospores of Phytophthora capsici, Phytophthora citrophthora and Phytophthora parasitica. As dimethomorph has never been used before in the growing of papaya locally and has a mode of action different to either potassium phosphonate or metalaxyl-M (Albert et al. 1988) which are currently used by the Australian papaya industry to manage Phytophthora root rot, it is unlikely the lack of efficacy was due to fungicide resistance.

In our experiments, copper hydroxide at rates of application of 375-600 g a.i./ $100 \mathrm{~L}$ consistently provided an extremely high level of disease control. However the regular use of copper fungicides particularly at high rates of application raises concerns of copper accumulation in soils and in crops and a potential risk to human health (Khan et al. 2013; Kelepertzis, 2014). Consequently using copper hydroxide in a spray program with the other effective chemicals would not only provide a high level of disease control but also reduce the potential risk to consumer health and the environment. In 2014, the results of our research were used to obtain a minor use permit for copper hydroxide at $375 \mathrm{~g}$ a.i. $/ 100 \mathrm{~L}^{-1}$ of water from the Australian Pesticide and Veterinary Association.

\section{Acknowledgements}

The authors gratefully acknowledge the financial support of Horticulture Australia Limited, Papaya Australia and Agri-Science Queensland, Department of Agriculture, Fisheries and Forestry. Further thanks to Mr. Mirko Karan for his technical assistance, and Department of Agriculture, Fisheries and Forestry staff at South Johnstone Research Station for their co-operation in this work.

\section{References}

Albert, G., Curtze, J., Drandarevski, C.A., 1988. Dimethomorph (CME 151), a nove curative fungicide. Proc. 1988 Brighton Crop Prot. Conf.-Pest Dis. 1, 17-24.

Alvarez, A.M., Nelson, M.G., 1982. Control of Phytophthora palmivora in papaya orchards with weekly sprays of chlorothalonil. Plant Dis. 66, 37-39.

Alvarez, A.M., Hylin, J.W., Ogata, J.N., 1977. Postharvest diseases of papaya reduced by biweekly orchard sprays. Plant Dis. Report. 61, 731-735.

CropLife Australia, 2013. Fungicide Resistance Management Strategies. Available at: http://www.croplifeaustralia.org.au [Valid as at 5 September 2013].

CDMS, 2014. 'Crop Data Management Systems, Inc.' Syngenta Crop Protection, LLC Specimen Label, SCP 50534-188A-L1J0114. Available at: http://www.cdms.net/ labelsMsds/.

Chay-Prove, P.M., 2000. 'Papaw Information Kit, Agrilink Series: Your Growing Guide to Better farming.' (Queensland Horticulture Institute, Department of Primary Industries: Brisbane, Queensland).

Diczbalis, Y., Williams, R., Hickey, M., 2012. Industry Situation Statement Papaya. National Horticultural Research Network.

Hamill, S.D., 1987. Fruit rot of papaw caused by Phytophthora palmivora in Queensland. Australas. Plant Pathol. 16, 22.

Hunter, J.F., Buddenhagen, I.W., 1969. Field biology and control of Phytophthora parasitica on papaya (Carica papaya) in Hawaii. Ann. Appl. Biol. 63, 53-60.

Hunter, J.E., Kunimoto, R.K., 1973. Dispersal of Phytophthora palmivora sporangia by wind-blown rain. Phytopathology 64, 202-206.

Kelepertzis, E., 2014. Accumulation of heavy metals in agricultural soils of Mediterranean: insights from Argolida basin, Peloponnese, Greece. Geoderma 221-222, 82-90.

Khan, K., Lu, Y., Khan, H., Ishtiaq, M., Sardar, K., Waqas, M., Luo, W., Wang, T., 2013. Heavy metals in agricultural soils and crops and their health risks in Swat District, northern Pakistan. Food Chem. Toxicol. 58, 449-458.

Ko, W., 1982. Biological control of Phytophthora. Plant Dis. 66, 446-448.

Lucas, J.A., Bower, L.A., Coffey, M.D., 1990. Fungicide resistance in soil-borne Phytophthora species. EPPO Bull. 20, 199-206.

Mathereon, M.E., Porchas, M., 2000. Impact of azoxystrobin, dimethomorph, fluazinam, fosetyl-al, and metalaxyl on growth, sporulation and zoospore cyst germination of three Phytophthora spp. Plant Dis. 84, 454-458.

Rebollar-Alviter, A., Madden, L.V., Ellis, M.A., 2007. Pre-and post-infection activity of azoxystrobin, pyraclostrobin, mefenoxam, and phosphate against leather rot of strawberry, caused by Phytophthora cactoram. Plant Dis. 91, 559-564.

Vawdrey, L.L., Westerhuis, D., 2007. Field and glasshouse evaluations of metalayl, potassium phosphonate, acibenzolar and tea tree oil in managing Phytophthora root rot of papaya in far northern Queensland, Australia. Australas. Plant Pathol. 36, 270-276.

Washington, W.S., McGee, P., 2000. Dimethomorph soil and seed treatment of potted tomatoes for control of damping-off and root rot caused by Phytophthora nicotianae var. nicotianae. Australas. Plant Pathol. 29, 46-51.

Worthing, C.R., Hance, R.J., 1991. 'The Pesticide Manual-a World Compendium.' ninth ed. British Crop Protection Council:Surrey, UK. 